\title{
AN AGENT-BASED SIMULATION APPROACH FOR DUAL TOLL PRICING OF HAZARDOUS MATERIAL TRANSPORTATION
}

\author{
Sojung Kim \\ Santosh Mungle \\ Young-Jun Son \\ Systems and Industrial Engineering \\ The University of Arizona \\ Tucson, AZ 85721, USA
}

\begin{abstract}
A dual toll pricing is a conceptual policy in which policy maker imposes toll on both hazardous materials (hazmat) vehicles as well as regular vehicles for using populated road segments to mitigate a risk of hazmat transportation. It intends to separate the hazmat traffic flow from the regular traffic flow via controlling the dual toll. In order to design the dual toll pricing policy on a highly realistic road network environment and detailed human behaviors, an extended BDI framework is employed to mimic human decision behaviors in great detail. The proposed approach is implemented in AnyLogic ${ }^{\circledR}$ agent based simulation software with using a traffic data of Albany, NY. Also, search algorithms in OptQuest ${ }^{\circledR}$ are used to determine the optimum dual toll pricing policy which results in the minimum risk and travel cost based on the simulation results. The result reveals the effectiveness of the proposed approach in devising a reliable policy under the realistic road network conditions.
\end{abstract}

\section{INTRODUCTION}

A hazardous material (hazmat) is defined as any substance or material that could adversely affect the safety of the public, handlers or carriers during transportation (Department of Transportation (DOT) 2013). Over the years, the hazmat transportation accidents have resulted in serious consequences in terms of deaths and major injuries. For instance, in the US, about 6,895 pounds of the anhydrous ammonia was released on the highway and near wooded area in 2009, from which one person was killed and seven people were injured because of ammonia poisoning. Besides, the anhydrous ammonia cloud caused temporary discoloration of vegetation in the area (PHMSA 2013). In addition to the human injuries, the hazmat transportation accidents have been responsible for monetary damages as well. For example, in 2012, in the US, there were 13,675 accidents caused by hazmat transportation with a total of $\$ 59$ million in damages. Among them, about $85.72 \%$ of the total hazmat accidents occurred on highway with a total of $\$ 49$ million in damages (PHMSA 2013). Therefore, for the public safety and economic consideration, the hazmat transportation on highway has received a keen attention of government such as the U.S. DOT.

Currently, government agencies in North America and Europe are trying to mitigate risk associated with the hazmat transportation on a road network by separating the hazmat traffic flow from normal traffic flow, especially high-density traffic flows. An example of this is the ban on trucks carrying nonradioactive hazmat on certain road segments (e.g. Texas Department of Transportation 2009 has a list of prohibited roads for Texas). In the literature, these types of policies are categorized into network-design (ND) policy. Significant research works have been done in this field to minimize hazmat transportation risk (e.g., Kara and Verter 2004). The ND policy is very effective to restrict hazmat traffic from highly 
dense regular traffic flow. However, the main limitation of the ND policy is not to consider the carriers' priorities such as a travel cost and wastes the usability of certain road segments. Moreover, only restricting certain road segments sometimes cannot rationally adjust the hazmat flows to areas with less risk (Wang et al. 2011).

Accordingly, an alternative policy tool, toll-setting policy (TS) which is a more flexible restriction policy for hazmat shipments than the ND policy, was proposed by Marcotte et al. (2009) to deter hazmat carriers from using certain road segments via toll pricing. Unlike the ND policy, the TS policy allows a government agency to consider the drivers' and carriers' priorities such as drivers' preference to avoid the road which has a high risk, and carrier companies try to achieve more profit by choosing the least cost path that reduces an operational cost (Pécheux et al. 2004), simultaneously. Recently, Wang et al. (2011) suggested a dual toll pricing framework to control both regular and hazmat traffic flows for the public safety since hazmat carriers are not only a part of the hazmat traffic flows, but also belong to, and cannot be separated from the regular traffic flows. By separating the hazmat traffic from the heavy-congestion regular traffic flows, the dual toll policy tries to mitigate severe accident risks and to avoid peak-time traffic congestions. However, the existing research works have some unrealistic assumptions, for example, individual driver's behavior (e.g. route planning behavior) is the same as others and the driver has perfect information of the current status of the network. Thus, in order to design and evaluate a more reliable dual toll pricing policy, this paper adopts the extended Belief-Desire-Intention (BDI) framework which is one of the well-known models to mimic a human decision behavior (Lee, Son, and Jin 2010). Since the extended BDI framework is able to illustrate a human reasoning process based on perceived information in a greater detail, it has been successfully implemented in various fields such as crowd management system (Lee, Son, and Jin 2010; Shendarkar et al. 2008) and manufacturing system (Zao and Son 2008). In this paper, this framework will demonstrate an individual driver's route choice behavior with imperfect information, which is implemented in the agent based simulation model.

The rest of the paper is organized as follows. Section 2 briefly describes the background of the extended BDI framework and driver's route choice behavior under the framework. In Section 3, the optimization formulation for the dual toll pricing is presented. Section 4 discusses the experimental results on a case study of road network in Albany district of New York State. Finally, we conclude our research works in Section 5 with suggested future works.

\section{A DRIVER'S ROUTE CHOICE BEHAVIOR UNDER THE EXTENDED BDI FRAMEWORK}

\subsection{Extended BDI Framework}

As mentioned in Section 1, in order to mimic realistic drivers' route choice behaviors, we adopt the extended BDI framework which is a unified framework involving both the decision-making and decisionplanning functions to represent more psychological natures of the human (Lee, Son, and Jin 2010). The framework consists of four main components: Belief module, Emotion module, Desire module, and Decision making module (see Figure 1). Belief module represents a perceptual process which generates beliefs from the environment. From Beliefs, the human generates desires (e.g. goals or hoping for an outcome) through the desire generator in the Desire module. If a human wishes to achieve a certain desire, then it becomes an intention (Rao and Georgeff 1998). Once an intention is selected from desires, the real-time planner generates a multi-stage plan, and the Decision Executor executes the plan in multi-stage. Moreover, the Emotional module contains the Confidence Index (CI) and the Instinct Index (II). The CI is updated based on the deviation between what is predicted during the planning stage and the reality during the execution stage, and affects the execution behavior of the human. If there is a situation under a high II (e.g. decisions to be made with time pressure), the human would make a decision based on his/her long-term memory (part of belief) instead of going through the entire decision planning and execution process that is mentioned in the previous sentences. 


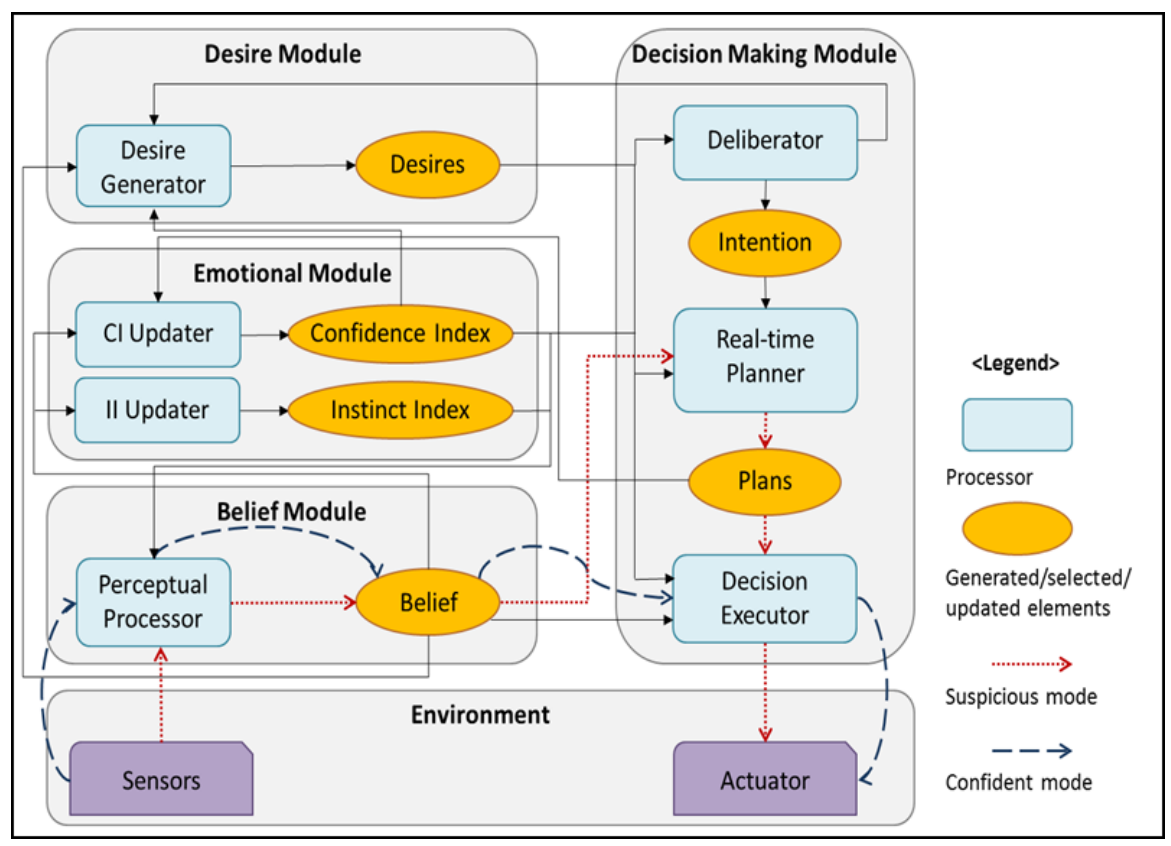

Figure 1: Components of the Extended BDI Framework (Zhao and Son 2008; Lee, Son, and Jin 2010)

\subsection{BDI Route Choice Model}

In this paper, we consider three types of drivers: 1) a risk averse of regular drivers who has higher preference on road risk than travel cost; 2) a risk taker of regular drivers who has higher preference on travel cost than road risk; and 3) a hazmat driver who only cares about travel cost related to own profit. The extended BDI framework is adopted to mimic the drivers' route choice behavior regarding their own preferences and beliefs about road conditions (e.g. traffic flow of regular vehicles and hazmat truck frequency). Especially, the drivers' the route planning behavior based on their perceived information is designed under the extended BDI framework. Figure 2 shows the sequence diagram of a driver's route planning.

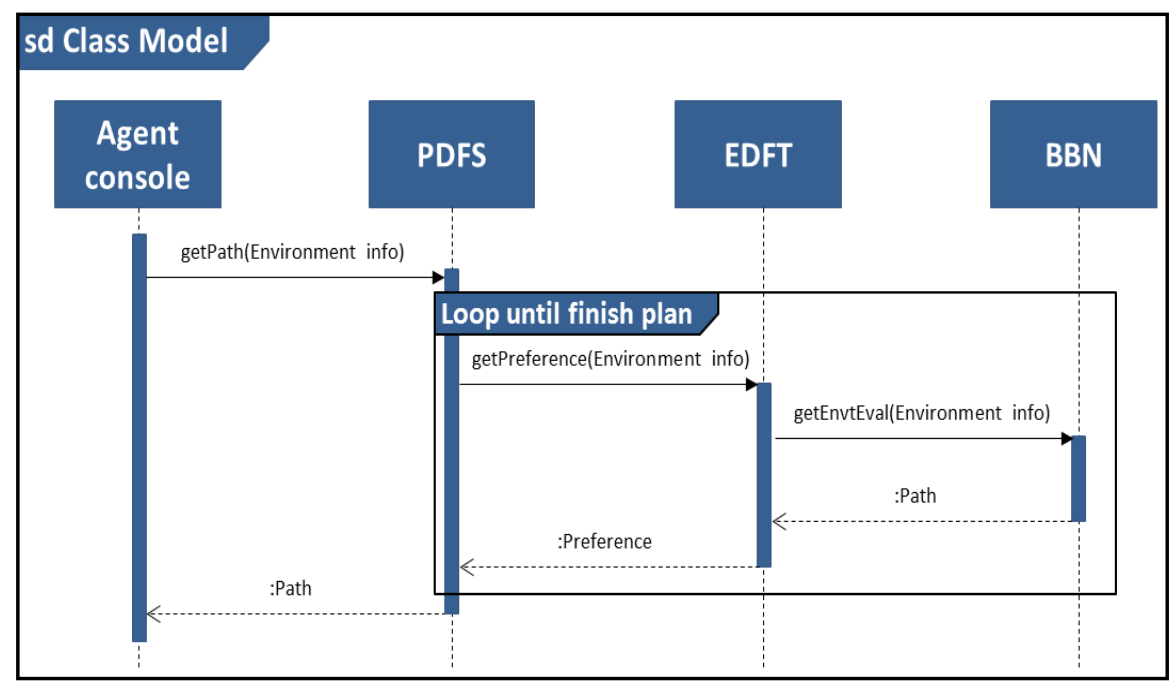

Figure 2: Sequence diagram of the driver's route planning (Lee, Son, and Jin 2010) 
First, Bayesian belief network $(\mathrm{BBN})$ in Perceptual Processor is used to generate beliefs considering an individual perception process. In fact, since the BBN is a probabilistic inference model based on an individual driver's experience and preference, each driver can have different Beliefs on a road situation. In this paper, we assume that all the drivers of the regular vehicle consider two main attributes (e.g. travel cost and road risk) which are related to several environmental variables such as distance from destination, free flow travel time, traffic flow, hazmat truck frequency, and toll price. Figure 3 shows the BBN structure of a regular driver agent.

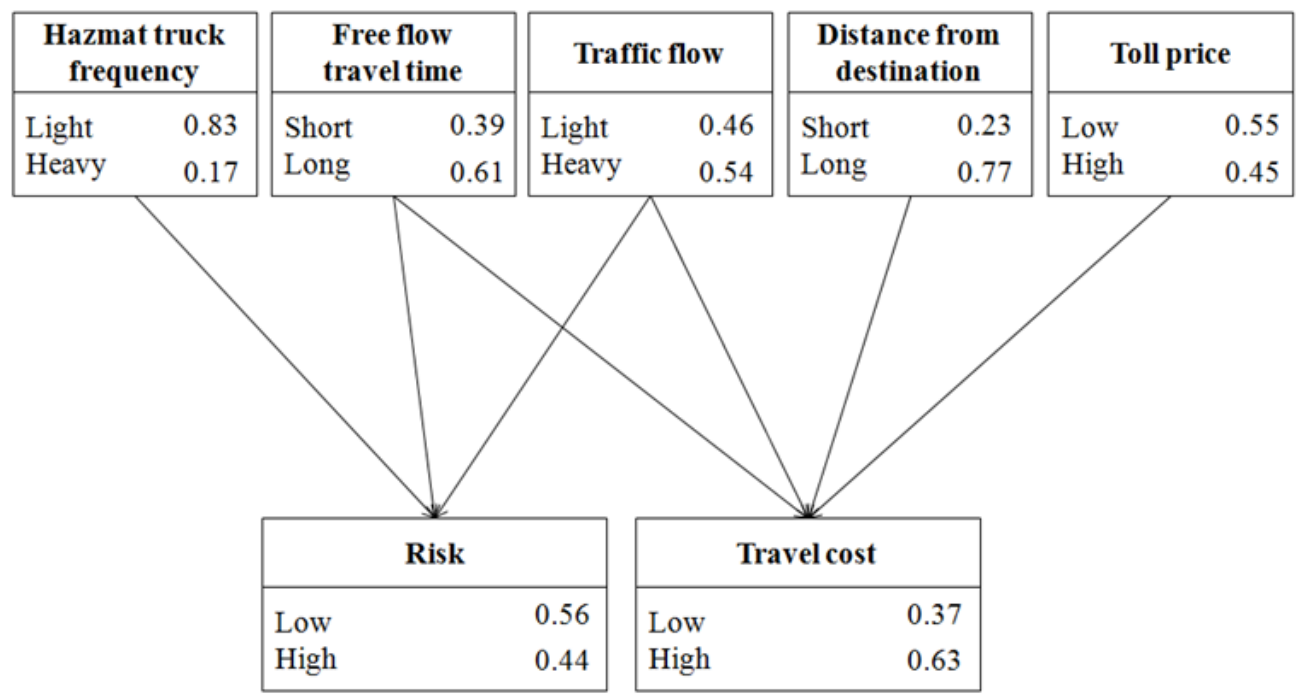

Figure 3: Bayesian Belief Network (BBN) of a regular driver agent

Second, once beliefs about attributes (i.e. risk and travel cost) are generated by BBN inference, Extended Decision Field Theory (EDFT) calculates the choice probability of linked arcs at the intersection. Originally, EDFT depicts a dynamic evolution of presence among options during the deliberation time using a linear system formulation (Busemeyer and Diederich 2002; Lee, Son, and Jin 2008):

$$
P(t+h)=S \times P(t)+C \times M(t+h) \times W(t+h)
$$

Where, $P(t)^{T}=\left(P_{1}(t), P_{2}(t), \ldots, P_{N_{i}}(t)\right)$ denotes the preference state in which $P_{i}(t)$ represents the strength of preference for option $i$ at time $t<T_{D}$ and $T_{D}$ is the time when final decision is made. $N_{i}$ is the total number of options. The preference state is updated at every time step $h$. The stability matrix $S$ provides the effect of the preference at the previous state (the memory effect) and the effect of the interactions among the options. The value matrix $M\left(N_{i} \times B\right.$ vector, $B$ is the number of attributes $)$ represents the subjective evaluations (perceptions) of a decision-maker for each option on each attribute. The value matrix $M(t)$ given by the Bayesian belief network (BBN). Besides, $B$ is 2 in our case (i.e. risk and travel cost). The weight vector $W(t)(B \times 1$ vector) allocates the weights of attention corresponding to each column (attribute) of $M$. The matrix $C\left(N_{i} \times N_{i}\right.$ vector) is the contrast matrix comparing the weighted evaluations of each option, $M \times W(t)$ (Lee, Son, and Jin 2008). Table 1 reveals the weight vector $W(t)$ with different types of regular drivers. 
Kim, Mungle, and Son

Table 1: The weight vector $W(t)$ of regular drivers

\begin{tabular}{|c|c|c|}
\hline Driver Type & Risk Averse & Risk Taker \\
\hline$W(t)=\left[\begin{array}{c}W_{\text {risk }}(t) \\
W_{\text {travelcost }}(t)\end{array}\right]$ & {$\left[\begin{array}{c}\text { uniform }(0.5,0.7) \\
1-W_{\text {risk }}(t)\end{array}\right]$} & {$\left[\begin{array}{c}\text { uniform }(0.3,0.5) \\
1-W_{\text {risk }}(t)\end{array}\right]$} \\
\hline
\end{tabular}

However, a driver of Hazmat vehicle only considers travel cost as an attribute since the intention to drive is to increase the benefit or reducing the cost. Thus, the four environmental variables such as distance from destination, free flow travel time, traffic flow and toll price are considered. This implies that the weight vector $W_{\text {travelcost }}(t)=1$. As a result, by using the value matrix $M(t)$ and the weight vector $W(t)$, EDFT calculates preference values considering the number of links on the intersection (i.e. the number of options) and gives the choice probability by normalizing the preference values.

Last, Probabilistic Depth First Search (PDFT) method, which is a probabilistic searching algorithm in graph which starts at the root and explores as far as possible along each branch before backtracking (Lee, Son, and Jin 2010), generates a route plan for a driver agents based on the choice probability information given by EDFT. Therefore, the driver agent can get a route plan based on each driver's perceived information on the road network. In addition, the proposed route planning model is implemented in AnyLogic $₫$ agent based simulation software.

\section{DESIGN AND DEVELOPMENT OF A DUAL TOLL PRICING POLICY}

In this paper, search algorithms available in OptQuest ${ }^{\circledR}$ are used to find the optimal/near optimal toll pricing values that result in the minimum risk and travel cost based on the collected information from agent based simulation. The OptQuest ${ }^{\circledR}$ incorporates a combination of three meta-heuristics (Glover, Kelly, and Laguna 1999): scatter search (SS), tabu search (TS), and neural networks (NN). Figure 4 shows a pseudo code of the proposed process to find the optimum dual toll pricing policy using the extended BDI framework. In the optimization process, once the OptQuest ${ }^{\circledR}$ sets the dual toll pricing policy, the agent based simulation, which includes extended BDI framework to address the route planning behavior for hazmat and regular driver, is executed. Since the toll price has an impact on the driver's route choice behavior, it affects the hazmat and regular traffic. More specifically, tolls encourage drivers to choose a less populated road according to the carrier's own selection due to economic consideration. The agent based simulation collects the data such as hazmat traffic flow and regular traffic flow, and average travel time of a hazmat and regular vehicle for a certain link. This data is collected when the simulation is in the steady state (i.e. convergence of traffic flows of the road network). As a result, the proposed approach has a feedback loop that means the agent based simulation model and optimization algorithm keeps running until it finds the optimal/near optimal toll price with minimum risk and travel time. Once the process reaches to specified iterations or no significant improvement in solutions is occurred, the optimization process is terminated. 
1: INITIALIZE total number of regular vehicles $u$ and hazmat vehicles $v$ and a range of the toll pricing policy for regular vehicles $\alpha$ and hazmat vehicles $\beta$

2: REPEAT

3: $\quad$ SET a toll price policy $\left(I_{t}\right)$

4: $\quad$ RUN an agent based simulation model with the extended BDI framework

5: IF the simulation is in steady state THEN

6: $\quad$ COMPUTE the value of objective function $f\left(I_{\mathrm{t}}\right)$

7: $\quad$ IF $f\left(I_{\mathrm{t}}\right)<f\left(I_{\mathrm{t}-1}\right)$ THEN

8: $\quad$ SAVE $f\left(I_{\mathrm{t}}\right)$ and output of the simulation model (e.g. traffic flow of each link) $\left(O_{\mathrm{t}}\right)$

9: UNTIL the objective function does not have significant improvement $\left(\left|f\left(I_{\mathrm{t}}\right)-f\left(I_{\mathrm{t}-1}\right)\right|<\theta\right)$

10: RETURN $f\left(I_{\mathrm{t}}\right)$ and $O_{\mathrm{t}}$

Figure 4: Pseudo code of the dual toll pricing policy optimization based on the extended BDI framework

\subsection{Optimization Formulation}

In this section, we present a mathematical formulation for dual toll pricing problem. Let $G=(N, A)$ be a network, where $N$ and $A$ denote the set of nodes and links, respectively. Consider we have OD pair sets for both regular and hazmat transportation, denoted by $K$ and $Q$ respectively. Corresponding to each OD pair $k \in K$ or $q \in Q$, there is a demand vector $b^{\mathrm{k}}$ or $d^{\mathrm{k}}$ respectively. For each demand vector $k$ and $q$, there exist arc flow vector $x^{\mathrm{k}}$ and $y^{\mathrm{q}}$. The sum of all regular OD pair flows is the regular aggregate flow $v$ and sum of all hazmat OD pair flows is the hazmat aggregate flow $u$.

The feasible flow for the network is defined as follows:

$$
\begin{aligned}
& V=\left\{v: v=\sum_{k \in K} x^{k}, A x^{k}=b^{k}, x^{k} \geq 0 \forall k \in K\right\} \\
& U=\left\{u: u=\sum_{q \in Q} y^{q}, A y^{q}=d^{q}, y^{q} \geq 0 \forall q \in Q\right\}
\end{aligned}
$$

According to Wardrop's first principle (Florian and Hearn 1995), the driver wants to minimize his or her individual cost by choosing the least cost link as he or she sees from a map of the existing traffic flow. This is known as a user equilibrium which can be stated as a variational inequality problem. For example, let's assume that a driver only consider travel time as his/her travel cost. A traffic flow $\bar{v} \in V$ of regular vehicles is the network user equilibrium if and only if $\bar{v}$ satisfies the following variational inequality:

$$
s(\bar{v}+\bar{u})^{T}(v-\bar{v}) \geq 0 \quad \forall v \in V
$$

where $\mathrm{s}(\cdot)$ is travel time function which is given by the simulation model. Similarly, for a given $\bar{v} \in V$, a traffic flow $\bar{u} \in U$ of hazmat truck is the network user equilibrium if and only if $\bar{u}$ satisfies the following variational inequality:

$$
s(\bar{v}+\bar{u})^{T}(u-\bar{u}) \geq 0 \quad \forall u \in U
$$

The above equilibrium flows $\bar{u}$ and $\bar{v}$ are identical to the system optimum which is a solution of the following linear program: 


$$
\begin{aligned}
& \bar{u}=\arg \min _{u \in U}[s(\bar{v}+\bar{u})]^{T} u \\
& \bar{v}=\arg \min _{v \in V}[s(\bar{v}+\bar{u})]^{T} v
\end{aligned}
$$

In the dual toll pricing model, we force drivers to change their behaviors by a toll imposed on the highway to achieve the system optimum. After charging the toll $\alpha$ for the regular traffic flow and $\beta$ for the hazmat traffic flow, the tolled user optimum problem becomes:

$$
\begin{array}{ll}
\left(s(\bar{v}+\bar{u})^{T}+\alpha\right)(v-\bar{v}) \geq 0 & \forall v \in V \\
\left(s(\bar{v}+\bar{u})^{T}+\beta\right)(u-\bar{u}) \geq 0 & \forall u \in U
\end{array}
$$

In reality, the driver wants to minimize the travel time by choosing the shortest link from the existing traffic flow map. In this paper, the average travel time for the vehicle on link $a S_{a}\left(v_{a}+u_{a}\right)$ is given by simulation model, where $v_{a}$ is the traffic flow of the regular vehicles for link $a$ and $u_{a}$ is the traffic flow of the hazmat vehicles for link $a$, respectively.

Moreover, for the risk of hazmat vehicles, we include a duration-population-frequency risk function that is similar to risk function of Cekyay and Verter (2010):

$$
R_{a}\left(v_{a}, u_{a}\right)=S_{a}\left(v_{a}+u_{a}\right) \rho_{a} u_{a}
$$

where $\rho_{a}$ is the population exposure along the link $a$. We considering the risk caused only by hazmat trucks accidents, but the amount of traffic on particular link $a$ would increase the probability of accidents of hazmat trucks. Therefore, it is obvious to write $R_{a}$ as a function of both $v_{a}$ and $u_{a}$.

Using the travel time and the risk function, the dual toll pricing problem can be formulated as follows:

$$
\min _{u, v, \alpha, \beta} J=w_{1}[R(v, u)]^{T} A+w_{2}[s(v+u)]^{T} v+w_{3}[s(v+u)]^{T} u
$$

Subject to

$$
\begin{array}{ll}
(s(v+u)+\alpha)^{T}(t-v) \geq 0 & \forall t \in V \\
(s(v+u)+\beta)^{T}(r-u) \geq 0 & \forall r \in U \\
v \in V & \\
u \in U & \\
\alpha, \beta \geq 0 &
\end{array}
$$

where $w_{1}, w_{2}$, and $w_{3}$ are the weights for risk, travel delay of regular vehicle, and travel delay of hazmat trucks, and $A=(1)_{a \in A}$.

In the above formulation, the objective function Eq. (1) tries to minimize the hazmat risk, travel delay of regular vehicle and hazmat vehicle. The constraint Eq. (2) ensures that $v$ is tolled user optimum flow with respect to toll $\alpha$. The constraint Eq. (3) ensures that $u$ is tolled user optimum flow with respect to toll $\beta$. The constraint Eq. (4) and Eq. (5) ensures that $v$ and $u$ is feasible aggregate flow. Constraint Eq. (6) makes sure that toll cost for regular and hazmat traffic flow always greater or equal to zero. 


\section{A CASE STUDY OF ALBANY ROAD NETWORK}

In this paper, we consider route data of an Albany road network in the New York State in order to demonstrate the efficiency of the proposed dual toll pricing approach. The agent based simulation model has been developed in AnyLogic 6.8.0 software. More detailed information of the simulation model is addressed in Section 4.1. In addition, the results of our experiment will be discussed in Section 4.2.

\subsection{Experimental Setting}

We use route distance and daily traffic data of Albany in the New York State as shown in Figure 5. The road network is comprised of 12 nodes (link intersections) and 18 links. Based on the proposed model, the experiment is conducted with single hazmat type and two types of regular drivers namely risk-averse and risk-taker. For each experiment, the total number of regular vehicle driver agents is taken as 1000 (each regular driver type has 500 agents) and the number of simulation replications is set to 10 . In addition, we assume that each driver moves from the origin node to the destination node continuously (see Figure 5). In other words, when the agent arrives at its destination, it starts again from the origin node with its previous knowledge. The detailed information about parameter values and data is described in Appendix A.

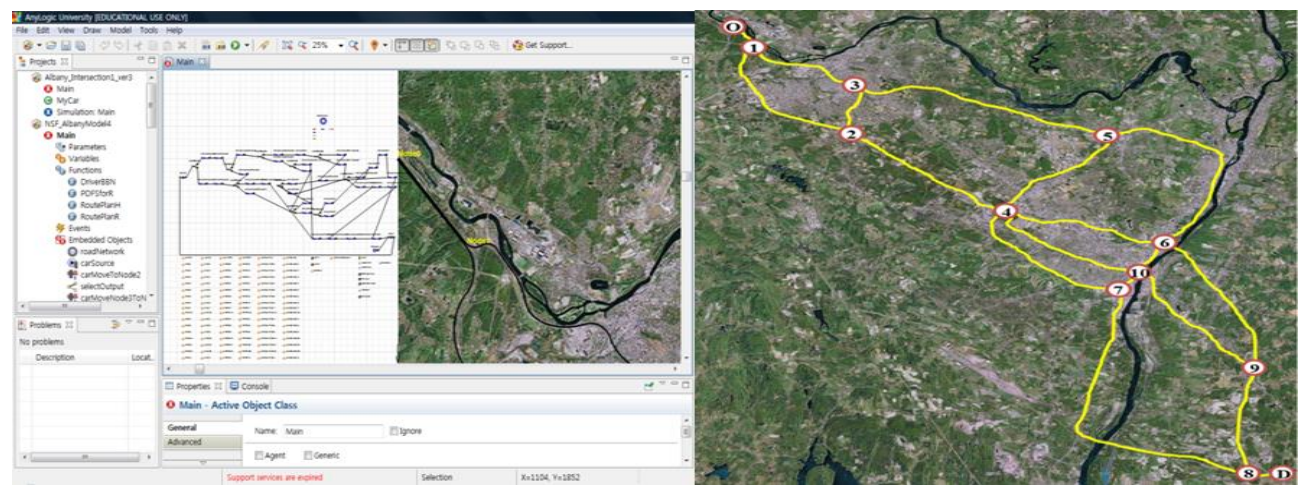

Figure 5: Snapshot of simulation model (in AnyLogic) and route map of Albany

\subsection{Results and Discussions}

The proposed agent based simulation model evaluates the impacts of toll pricing values on traffic flow including hazmat and regular and the best one is obtained via using OptQuest ${ }^{\circledR}$ that minimizes risk and travel time. The experiments are performed on the desktop: Intel Core2 Duo P8400 with 2.26GHz. Each replication in the agent based simulation takes 1143 seconds ( $95 \%$ C.I. half width: 812 ) to get converged traffic flow for each vehicle including hazmat and regular. Moreover, the total optimization time of OptQuest ${ }^{\circledR}$ takes 15.88 hours (with 50 iterations and 10 replications).

In order to understand the impact of the dual toll pricing policy on hazmat risk and travel time (delay), we compare the performance with the minimum travel cost of regular traffic $\left(v^{\text {so }}\right)$ and the minimum risk flow of hazmat traffic $\left(u^{\mathrm{so}}\right)$ given the regular traffic $\left(v^{\mathrm{so}}\right)$. For further validation of the proposed approach, we adopt the same metrics used by Wang et al. (2011).

- Change of Risk: $\frac{R\left(u^{*}, v^{*}\right)-R\left(u^{s o}, v^{s o}\right)}{R\left(u^{s o}, v^{s o}\right)}$ 
- Change of Delay (regular vehicle: $\mathrm{R}): \frac{D\left(v^{*}\right)-D\left(v^{s o}\right)}{D\left(v^{s o}\right)}$

- Change of Delay (hazmat vehicle: $\mathrm{H}): \frac{D\left(u^{*}\right)-D\left(u^{s o}\right)}{D\left(u^{s o}\right)}$

- Tolls Collected (regular vehicle: $\mathrm{R}): \alpha^{T} v^{*}$

- Tolls Collected (hazmat vehicle: $\mathrm{H}$ ): $\beta^{T} u^{*}$

Where,

$$
\begin{aligned}
& D\left(v^{s o}\right)=s\left(v^{s o}+u^{s o}\right)^{T}\left(v^{s o}\right) \\
& D\left(v^{*}\right)=s\left(v^{*}+u^{*}\right)^{T} v^{*} \\
& \left(u^{*}, v^{*}\right)=\arg \min _{u, v} J \\
& v^{s o}=\arg \min _{v} \sum_{a \in A}\left[S_{a}\left(v_{a}+u_{a}\right) v_{a}\right] \\
& u^{s o}=\arg \min _{u}\left\{w_{1}\left[R\left(v^{s o}, u\right)\right]+w_{2}\left[S\left(v^{s o}+u\right)\right] v^{s o}+w_{3}\left[S\left(v^{s o}+u\right)\right] u\right\}
\end{aligned}
$$

With these measures, we compare the dual tolled traffic flows $\left(u^{*}, v^{*}\right)$ with the traffic flows $\left(u^{s o}, v^{s o}\right)$ at regular traffic's system optimum.

Table 2 shows the comparison results with various $w_{1}$ when $w_{2}=1$ and $w_{3}=1$. In this case, 500 risktaker vehicles $(50 \%)$ and 500 risk-averse vehicles $(50 \%)$ of regular vehicles are considered. The number of hazmat vehicles is taken as 100 . Considering the amount of the collected tolls, the difference between hazmat toll and regular toll should be large enough as $w_{1}$ increases. This is because the dual toll policy motivates the hazmat traffic flow to separate from the regular traffic flow. Therefore, the travel time of hazmat vehicle decreases since the hazmat vehicle selects a different route that has low frequency of regular traffic. In addition, the risk decreases as $w_{1}$ increases, while travel time of regular traffic is increased because a regular vehicle has limited options of its route related to road risk.

Table 2: Sensitive analysis about $w_{1}$ given $w_{2}=1$ and $w_{3}=1$

\begin{tabular}{|c|c|c|c|}
\hline$\left(w_{1}, w_{2}, w_{3}\right)$ & $\left(10^{-3}, 1,1\right)$ & $\left(10^{-1}, 1,1\right)$ & $(1,1,1)$ \\
\hline Change of risk & $(-16.2219,15.8755)$ & $(-16.4742,15.6216)$ & $(-16.5257,15.5733)$ \\
\hline Change of delay $(\mathrm{R})$ & $(-0.1989,-0.1751)$ & $(-0.0945,-0.0721)$ & $(0.1161,0.1391)$ \\
\hline Change of delay $(\mathrm{H})$ & $(0.1807,0.2031)$ & $(0.053,0.0762)$ & $(0.0346,0.0554)$ \\
\hline Toll collected $(\mathrm{R})$ & $(519.42,520.58)$ & $(1058.84,1061.16)$ & $(1058.84,1061.16)$ \\
\hline Toll collected $(\mathrm{H})$ & $(0.0,0.0)$ & $(8.4922,9.5078)$ & $(8.4911,9.5089)$ \\
\hline
\end{tabular}

Moreover, Table 3 and Table 4 show the different cases when $w_{2}$ and $w_{3}$ is changed, respectively. Through these experiments, we intend to show that the travel time of each vehicle is directly related to its toll policy. The road risk gets increased with $w_{2}$ and $w_{3}$. We found that the regular toll affects not only the regular traffic but also the hazmat traffic. For example, if the regular toll is imposed on certain link, the regular drivers will try to choose another less populated link from economic point of view, and hence regular traffic will get reduced on that particular link. This decreases an accident probability for hazmat vehicle. It means that the road risk can be reduced by the regular toll policy. Therefore, we need to be more careful in designing the regular toll price policy which controls the traffic flow of each vehicle including hazmat and regular. 
Kim, Mungle, and Son

Table 3: Sensitive analysis about $w_{2}$ given $w_{1}=1$ and $w_{3}=1$ (500 Risk takers)

\begin{tabular}{|c|c|c|c|}
\hline$\left(w_{1}, w_{2}, w_{3}\right)$ & $(1,1,1)$ & $\left(1,10^{2}, 1\right)$ & $\left(1,10^{3}, 1\right)$ \\
\hline Change of risk & $(-16.5257,15.5733)$ & $(-16.2219,15.8755)$ & $(-16.2219,15.8755)$ \\
\hline Change of delay $(\mathrm{R})$ & $(0.1161,0.1391)$ & $(-0.1989,-0.1751)$ & $(-0.1989,-0.1751)$ \\
\hline Change of delay $(\mathrm{H})$ & $(0.0346,0.0554)$ & $(0.1807,0.2031)$ & $(0.1807,0.2031)$ \\
\hline Toll collected $(\mathrm{R})$ & $(1058.84,1061.16)$ & $(519.42,520.58)$ & $(519.42,520.58)$ \\
\hline Toll collected $(\mathrm{H})$ & $(8.4911,9.5089)$ & $(0.0,0.0)$ & $(0.0,0.0)$ \\
\hline
\end{tabular}

Table 4: Sensitive analysis about $w_{3}$ given $w_{1}=1$ and $w_{2}=1$ (500 Risk takers)

\begin{tabular}{|c|c|c|c|}
\hline$\left(w_{1}, w_{2}, w_{3}\right)$ & $(1,1,1)$ & $\left(1,1,10^{2}\right)$ & $\left(1,1,10^{3}\right)$ \\
\hline Change of risk & $(-16.5257,15.5733)$ & $(-16.4888,15.6094)$ & $(-16.4888,15.6094)$ \\
\hline Change of delay $(\mathrm{R})$ & $(0.1161,0.1391)$ & $(0.1187,0.1415)$ & $(0.1187,0.1415)$ \\
\hline Change of delay $(\mathrm{H})$ & $(0.0346,0.0554)$ & $(-0.0394,-0.0178)$ & $(-0.0394,-0.0178)$ \\
\hline Toll collected $(\mathrm{R})$ & $(1058.84,1061.16)$ & $(2768.33,2771.67)$ & $(2768.33,2771.67)$ \\
\hline Toll collected $(\mathrm{H})$ & $(8.4911,9.5089)$ & $(0.0,0.0)$ & $(0.0,0.0)$ \\
\hline
\end{tabular}

\section{CONCLUSIONS}

In this paper, we proposed a simulation-based optimization approach for dual toll pricing policy under the extended BDI framework to mitigate the hazmat transportation risk. Our main motivation was to design a more realistic dual toll pricing policy which controls both regular and hazmat traffic to lessen the transport risk. To this end, the extended BDI framework was adopted to mimic a driver's route choice behavior. We considered two types of driver, a risk-taker and a risk-averse for the regular traffic. The extended BDI framework had been implemented in AnyLogic ${ }^{\circledR}$ agent based simulation software. The proposed approach was then illustrated for dual toll pricing problem involving the real traffic data of Albany, NY. Furthermore, we used search algorithms in OptQuest ${ }^{\circledR}$ to perform the optimization. To validate our proposed approach, we compared our results from the agent based simulation with the existing dual toll pricing optimization approach by using same metric. The results validation showed that the proposed simulation based optimization approach enables us to develop a more reliable dual toll pricing policy with various drivers' preferences and decisions.

For future works, there are several directions that can be explored. Especially, in this paper, we used OptQuest ${ }^{\circledR}$ in AnyLogic ${ }^{\circledR}$ based on the weighted multi-objective formulation which includes a biasness of decision maker related to the weights for each sub-objective. As an alternate approach, the problem can be formulated as multi-objective and solved by Pareto-based multi-objective metaheuristics.

\section{ACKNOWLEDGMENTS}

This work has been supported by the National Science of Foundation under CMMI-1068866 and Federal Highway Administration under FHWA EAR DTFH61-10-R-00036.

\section{A SIMULATION PARAMETERS AND DATA}

Table A.1 and Table A.2 show the road network data of Albany in the New York State and the assumed parameter values of the simulation model, respectively. 
Kim, Mungle, and Son

Table A.1: Road network data

\begin{tabular}{|c|c|c|c|c|}
\hline \multicolumn{2}{|c|}{ Nodes } & \multirow{2}{*}{ Distance } & \multirow{2}{*}{ Free flow speed } & \multirow{2}{*}{$\begin{array}{c}\text { Population } \\
\text { density }\end{array}$} \\
\hline Start & End & & & \\
\hline Origin & 1 & 2.78 miles & 65 miles $/ \mathrm{hr}$. & $647 / \mathrm{mile}^{2}$ \\
\hline 1 & 2 & 8.15 miles & 65 miles/hr. & $647 / \mathrm{mile}^{2}$ \\
\hline 1 & 3 & 7.02 miles & 65 miles $/ \mathrm{hr}$. & $647 / \mathrm{mile}^{2}$ \\
\hline 2 & 4 & 6.1 miles & 65 miles/hr. & $1841 / \mathrm{mile}^{2}$ \\
\hline 3 & 2 & 3.01 miles & 65 miles/hr. & $1841 / \mathrm{mile}^{2}$ \\
\hline 3 & 5 & 8.86 miles & 65 miles $/ \mathrm{hr}$. & $1358 / \mathrm{mile}^{2}$ \\
\hline 4 & 6 & 5.89 miles & 65 miles $/ \mathrm{hr}$. & $7286 / \mathrm{mile}^{2}$ \\
\hline 4 & 7 & 5.72 miles & 65 miles/hr. & $2736 / \mathrm{mile}^{2}$ \\
\hline 4 & 10 & 5.93 miles & 65 miles $/ \mathrm{hr}$. & $2736 / \mathrm{mile}^{2}$ \\
\hline 5 & 4 & 5.33 miles & 65 miles $/ \mathrm{hr}$. & $1391 / \mathrm{mile}^{2}$ \\
\hline 5 & 6 & 9.77 miles & 65 miles/hr. & $2389 / \mathrm{mile}^{2}$ \\
\hline 6 & 9 & 8.14 miles & 65 miles $/ \mathrm{hr}$. & $238 / \mathrm{mile}^{2}$ \\
\hline 6 & 10 & 2.02 miles & 65 miles $/ \mathrm{hr}$. & $2847 / \mathrm{mile}^{2}$ \\
\hline 7 & 8 & 14.25 miles & 65 miles $/ \mathrm{hr}$. & $212 / \mathrm{mile}^{2}$ \\
\hline 8 & Destination & 1.9 miles & 65 miles $/ \mathrm{hr}$. & $148 / \mathrm{mile}^{2}$ \\
\hline 9 & 8 & 5.63 miles & 65 miles/hr. & $210 / \mathrm{mile}^{2}$ \\
\hline 10 & 7 & 1.49 miles & 65 miles $/ \mathrm{hr}$. & $4746 / \mathrm{mile}^{2}$ \\
\hline 10 & 9 & 6.76 miles & 65 miles $/ \mathrm{hr}$. & $1255 / \mathrm{mile}^{2}$ \\
\hline
\end{tabular}

Table A.2: Assumed parameter values in simulation model

\begin{tabular}{|c|c|}
\hline Parameter & Value \\
\hline Number of regular vehicles & 1000 \\
\hline Number of regular vehicles & 100 \\
\hline Number of iterations & 50 \\
\hline Number of replications & 10 \\
\hline Arrival rate of vehicles & 100 vehicles $/ \mathrm{hr}$. \\
\hline maximum acceleration rate & uniform $(10,12) \mathrm{feet} / \mathrm{sec}^{2}$ \\
\hline maximum deceleration rate & uniform $(-12,-8) \mathrm{feet} / \mathrm{sec}^{2}$ \\
\hline
\end{tabular}

\section{REFERENCES}

Busemeyer, J. R., and Diederich, A., 2002. "Survey of decision field theory." Math. Social Sci., 43, 345370.

Cekyay, B., and Verter, V., 2010. "Transportation of hazardous materials in urban areas.” Working paper, McGill University.

Department of Transportation (DOT), 2013. Hazardous Materials (HM). Accessed April 21. http://www.fmcsa.dot.gov/safety-security/hazmat/hm-theme.htm.

Florian, M., and Hearn, D., 1995. "Network equilibrium models and algorithms." Handb Oper Res Manag Sci., 8(1), 485-550. 
Glover, F., Kelly, J. P., and Laguna, M., 1999. "New advances for wedding optimization and simulation." In Simulation Conference Proceedings, 1, 255-260.

Kara, B. Y., and Verter, V., 2004. "Designing a Route Network for Hazardous Materials Transportation." Transportation Science, 38(2), 188-196.

Lee, S., Son, Y., and Jin, J., 2008. "Decision field theory extensions for behavior modeling in dynamic environment using bayesian belief network." Infor. Sci., 178(10), 2297-2314.

Lee, S., Son, Y., and Jin, J., 2010. "Integrated human decision making and planning model under extended belief-desire-intention framework." ACM Transactions on Modeling and Computer Simulation (TOMACS), 20(4).

Marcotte, P., Mercier, A., Savard, G., and Verter, V., 2009. "Toll Policies for Mitigating harzadous materials transport risk." Transport Sci., 43(2), 228-243.

Pécheux, K. K., Flannery, A., Wochinger, K., Rephlo, J., and Lappin, J., 2004. “Automobile Drivers' Perceptions of Service Quality on Urban Streets." Transportation Research Record: Journal of the Transportation Research Board, 1883, 167-175.

Pipeline and Hazardous Materials Safety Administration (PHMSA), 2013. Data and Statistics. Accessed April 21. http://www.phmsa.dot.gov/hazmat/library/data-stats.

Rao, A., and Georgeff, M., 1998. "Decision procedures for BDI logics." J. Logic Comput., 8(3), 293-343.

Shendarkar, A., Vasudevan, K., Lee, S., and Son, Y., 2008. "Crowd Simulation for Emergency Response using BDI Agents Based on Immersive Virtual Reality." Simulation Modelling Practice and Theory, $16(1), 1415-1429$.

Wang, J., Kang, Y., Kwon, C., and Batta, R., 2011. "Dual toll pricing for hazardous materials transport with linear delay." Networks and Spatial Economics, 12(1), 147-165.

Zhao, X., and Son, Y., 2008. "BDI-based human decision-making model in automated manufacturing systems." International Journal of Modeling and Simulation, 28(3), 347-356.

\section{AUTHOR BIOGRAPHIES}

SOJUNG KIM is a Research Assistant in the Department of Systems and Industrial Engineering at the University of Arizona. He received his Master in Industrial and Systems Engineering from Dongguk University, Republic of KOREA in 2010. His research interests include Agent based modeling \& simulation, Human decision making and Behavior modeling. He is a member of INFORMS, and IIE. His email address is sojungkim@email.arizona.edu and his web page is https://sites.google.com/site/sojungk8/.

SANTOSH MUNGLE is graduated with his master in Systems Engineering from the University of Arizona. He received his first master in Infrastructure Design and Management from Indian Institute of Technology Kharagpur in 2010. He worked as a Visiting Research Engineer at French National Institute for Research in Computer Science and Control (INRIA). His research interests include Heuristics, Multiobjective Optimization, and Simulation Modeling. He is a member of INFORMS. His email address is santoshmungle@gmail.com and his web page is https://sites.google.com/site/santoshmungle/.

YOUNG-JUN SON is a Professor of Systems and Industrial Engineering at the University of Arizona and Director of Advanced Integration of Manufacturing Systems and Technologies Center. His research focuses on the coordination of a multi-scale, networked-federated simulation and decision model needed for design and control in manufacturing enterprise, renewable energy network, homeland security, agricultural supply network, and social network. He has received several research awards such as the SME 2004 Outstanding Young Manufacturing Engineer Award, the IIE 2005 Outstanding Young Industrial Engineer Award, the IERC Conference Best Paper Awards (2005, 2008, 2009), and Best Paper of the Year Award in 2007 from IJIE. His email address is son@sie.arizona.edu. 